\title{
CHEMICAL ETCHING AND HARDNESS ANISOTROPY IN L- LYSINE MONOHYDROCHLORIDE DIHYDRATE CRYSTAL
}

\author{
P. V. Raja Shekar ${ }^{1}$, D. Madhavi Latha ${ }^{2,3,}$, Ch. Sateesh Chandra ${ }^{4}$ \\ and K. Kishan Rao ${ }^{5}$ \\ ${ }^{1}$ Department of Physics, School of Sciences, SR University, Warangal-506 371, Telangana, India \\ ${ }^{2}$ Department of Physics, National Institute of Technology, Warangal-506 004, Telangana, India \\ ${ }^{3}$ SSD Polymers, Machilipatnam-521 002, Andhra Pradesh, India \\ ${ }^{4}$ Department of Physics, Kakatiya Institute of Technology and Sciences, Warangal-506 015, \\ Telangana, India \\ ${ }^{5}$ Department of Physics, Kakatiya University, Warangal-506 009, Telangana, India \\ ${ }^{\square}$ Corresponding Author: madhavilatha25@gmail.com
}

\begin{abstract}
Optically transparent crystals of L-lysine monohydrochloride dihydrate (L-LMHCl), a potential semi-organic nonlinear optical crystal, were grown by the slow evaporation method. The crystals were characterized by powder XRD, FT-IR, and DSC to understand the structure, functional groups, and phase transitions respectively. The crystal surface exhibits growth features and is free from visible inclusions. The wet-chemical etching technique has been used to understand the etching kinetics as well as the dislocation density. A new prospective chemical etchant (acetic acid) has been developed to reveal the dislocations. The anisotropy is captured from the load-hardness curves by orienting the longer edge of the crystal face at $0^{\circ}$ and $45^{\circ}$ with respect to the indentation diagonal.

Keywords: Semi-organic Crystals, Functional Groups, Chemical Etching, Dislocations, Anisotropy

RASĀYAN J. Chem., Vol. 14, No.3, 2021
\end{abstract}

\section{INTRODUCTION}

Amino acid crystals play a vital role in the second harmonic generation and are good materials for nonlinear optical (NLO) applications. Amino acids, mixed with either organic or inorganic complexes, exhibit enhanced chemical, thermal, mechanical, and non-linear optical properties. ${ }^{1}$ A variety of amino acid families of crystals, to name a few, viz. L-arginine phosphate monohydrate, L-arginine tetrafluoroborate, L-arginine dihydrate, L-tyrosine hydrobromide, L-asparaginium picrate, L-alanine cadmium chloride, L-alanine formate, L-histidine nitrate, etc. have found to be possessing the desired properties. These enhanced properties are due to the presence of a proton donor carboxyl acid (-COO) and the proton acceptor amino $\left(-\mathrm{NH}_{2}\right)$ groups. ${ }^{2}$ In the solid-state, these exist as dipolar ions in which the carboxyl group is present as carboxylate ion, which makes amino acids suitable for NLO applications. ${ }^{3}$ Hence, amino acids are continuously being exploited for the formation of crystals by combining with different organic and inorganic compounds. L-lysine is one among them which leads to the formation of a potential semi-organic NLO crystal, L-lysine monohydrochloride dihydrate (L-LMHCl). A detailed survey of the literature suggests that reports on the growth (conventional and unidirectional) and characterization (spectral, electrical, optical, etc.) of pure $e^{4-7}$ and doped ${ }^{8-10}$ crystals are available. However, a comprehensive approach to understanding the surface features (for possible growth mechanism), wetchemical etching (for etching kinetics and dislocation density) and hardness anisotropy of these crystals is lacking. Hence, this article discusses the growth of L-LMHCl crystal and its characterization by X-ray Diffractometry (XRD), Fourier Transform Infrared Spectroscopy (FT-IR), Differential Scanning Calorimetry (DSC), optical microscopy, and hardness tests in the following sections.

\section{Crystal Growth}

\section{EXPERIMENTAL}

Single crystals of L-LMHCl were obtained from the slow evaporation of aqueous solutions using a constant temperature bath. In this method, the saturated solutions of about $500 \mathrm{~mL}$ were prepared at room 
temperature by dissolving approximately $58 \mathrm{~g} / 100 \mathrm{~mL}$ (from the solubility diagram) of the salt. These solutions are then uniformly transferred into three beakers and the temperature is raised to $40{ }^{\circ} \mathrm{C}$ and then cooled back slowly to $35^{\circ} \mathrm{C}$ over one hour to ensure complete dissolution. Necessary care has been taken to avoid thermal fluctuations, as these may lead to fluctuations in supersaturation and henceforth incorporation of inclusions or defects in crystals during growth. The beakers were covered with perforated sheets to control the evaporation rate. Self-nucleated seed crystals were allowed to grow at the base of the beaker and within ten days, crystals of dimensions $7 \times 4 \times 3 \mathrm{~mm}^{3}$ were obtained as shown in Fig.-1. The average growth rate measured along the longer edge of the crystals is found to be $0.9 \mathrm{~mm} / \mathrm{day}$. The crystals obtained were colorless, highly transparent without any visible inclusions, and nonhygroscopic in nature.

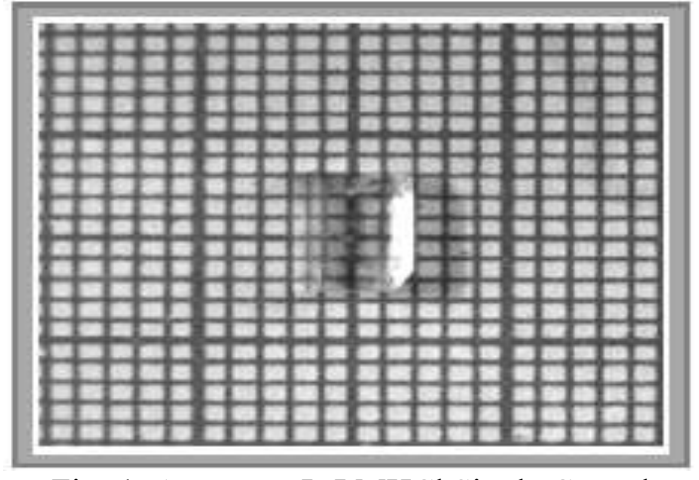

Fig.-1: As-grown L-LMHCl Single Crystal

\section{Investigations}

To determine the structure, powder $\mathrm{XRD}$ analysis was carried out using Philips (PW1830, CuK $\alpha$ radiation) diffractometer at a scanning rate of $0.02 \% \mathrm{~min}$. The FT-IR spectrum was recorded $(\mathrm{KBr}$ pellet technique) using Perkin Elmer (BX I) spectrometer over the range $400-4000 \mathrm{~cm}^{-1}$. Differential scanning calorimetry was carried with $8.4 \mathrm{mg}$ of the sample using Mettler Toledo (DSC 822 $2^{\mathrm{e}}$ ) at a heating rate of $10{ }^{\circ} \mathrm{C} / \mathrm{min}$. The surface studies, to understand growth mechanism and dislocation density, were carried out using a Magnus MLX microscope equipped with Motic (1000) camera. The hardness of the crystals was determined using Leitz-Wetzlar (miniload 2) Vickers microhardness tester (loads - 10 to $100 \mathrm{~g}$ and indentation time $\sim 15 \mathrm{sec}$ ).

\section{Confirmation Studies}

\section{RESULTS AND DISCUSSION}

The analysis of the diffraction pattern (Fig.-2) indicates that the crystals belong to monoclinic system with unit cell parameters as $\mathrm{a}=5.925 \AA, \mathrm{b}=13.293 \AA, \mathrm{c}=7.428 \AA$, and $\beta=97.54^{\circ}{ }^{4}$. The FT-IR spectrum of L-LMHCl is shown in Fig.-3. The absorption peak at $2930 \mathrm{~cm}^{-1}$ corresponds to the stretching vibrations of $\mathrm{NH}_{3}{ }^{+}$(symmetric) and $\mathrm{C}-\mathrm{H}$ (asymmetric) groups. The asymmetric $\mathrm{NH}_{3}$ bending vibration is observed at $2060 \mathrm{~cm}^{-1}$. The absorption peak at $1585 \mathrm{~cm}^{-1}$ indicates the presence of $\mathrm{CO}_{2}^{-}$asymmetric stretching modes, whereas the intense peak at $1507 \mathrm{~cm}^{-1}$ signifies the presence of $\mathrm{NH}_{3}^{+}$asymmetric bending vibrations. Symmetric stretching modes of the $\mathrm{CO}_{2}^{-}$group were observed at $1407 \mathrm{~cm}^{-1}$. The symmetric bending of the C-H group is observed at $1320 \mathrm{~cm}^{-1}$ and the band at $1150 \mathrm{~cm}^{-1}$ corresponds to the rocking of $\mathrm{NH}_{3}{ }^{+}$. Further, a small peak observed at $1030 \mathrm{~cm}^{-1}$ is attributed to the $\mathrm{C}-\mathrm{N}$ stretching vibrations involving a carbon of the structure and nitrogen of the amino group. The sharp peak at $996 \mathrm{~cm}^{-1}$ and the band at $940 \mathrm{~cm}^{-1}$ are assigned to $\mathrm{C}-\mathrm{O}$ stretching and $\mathrm{C}-\mathrm{C}$ stretching respectively. The intense peak at 861 $\mathrm{cm}^{-1}$ is attributed to C-C-N stretching. The wagging of $\mathrm{CO}_{2}^{-}$at $710 \mathrm{~cm}^{-1}$, torsion of $\mathrm{C}-\mathrm{OH}$ at around the band at $750 \mathrm{~cm}^{-1}$ and the torsion of C-C-C group at $429 \mathrm{~cm}^{-1}$, are observed. ${ }^{4,9,10}$ Fig.-4 shows the DSC thermogram consisting of a series of endothermic peaks. The crystal is thermally stable up to $67.51{ }^{\circ} \mathrm{C}$ without any phase transitions. An endothermic peak at $69.43{ }^{\circ} \mathrm{C}$ may be attributed to the loss of lattice water. Further, another major and sharp endothermic peak at $263.90{ }^{\circ} \mathrm{C}$ is due to the decomposition (melting point) of the crystal. ${ }^{4}$ The XRD, FT-IR, and DSC results indicate a good degree of crystallinity and thermal stability. 
RASĀYAN J. Chem.

Vol. 14 | No. 3 |1892-1898| July - September | 2021

\section{Surface Studies}

In the case of crystals obtained from solution growth, the surface microtopography reflects the final stage of growth, which takes place exclusively at the solid-liquid interface. Hence, when the crystal surfaces are observed through a microscope, in some cases, they reveal specific growth features such as spirals, hillocks, and striations, which gives an insight into the growth mechanism. For these studies, the asgrown L-LMHCl crystals (of about ten) were observed under an optical microscope. It is observed that most of the crystals reveal typical striations on the $\left(\begin{array}{lll}01 & \overline{1}\end{array}\right)$ face, which are parallel to the longer edge of the crystal and do not propagate from one end to another, as shown in Fig.-5a.

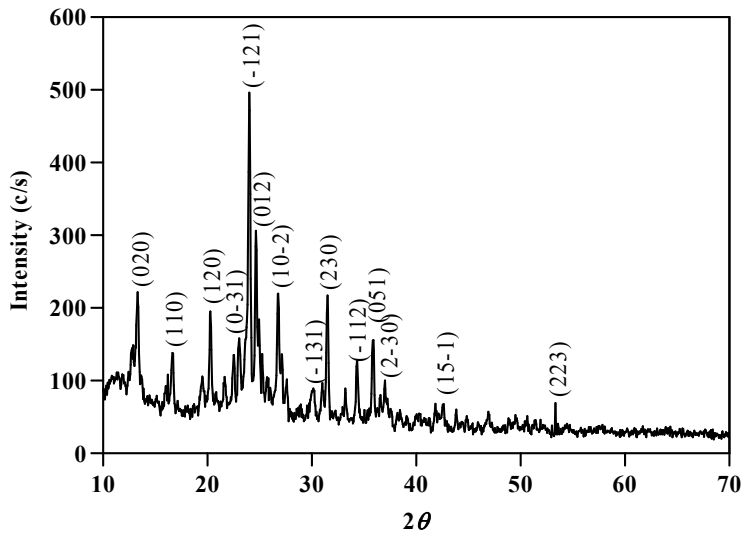

Fig.-2: Powder XRD Pattern of L-LMHCl Crystal

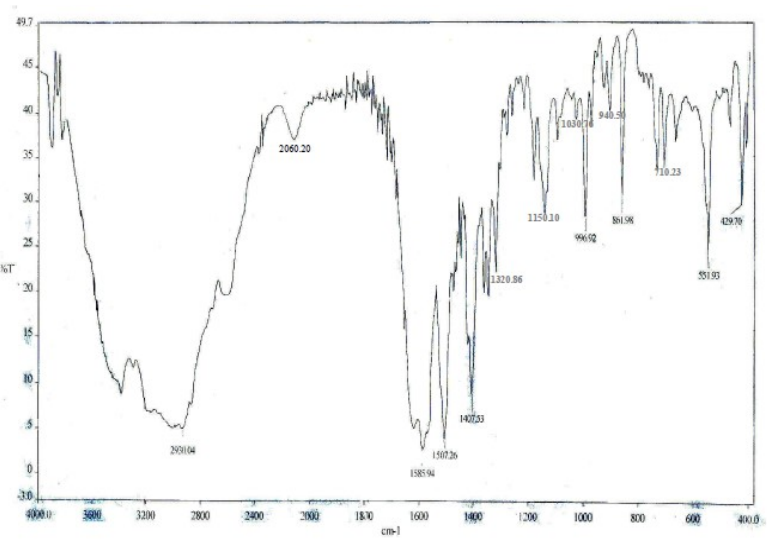

Fig.-3: FT-IR Spectrum of L-LMHCl

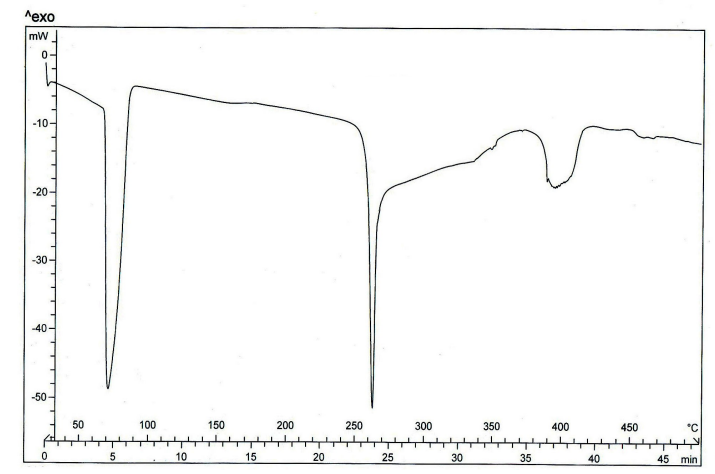

Fig.-4: DSC Thermogram of L-LMHCl

The striations may arise due to fluctuations in growth conditions due to temperature, cooling rate, and convection of the solution. ${ }^{11}$ The concentration of striations at the center of the crystal suggests that the growth process initiates at the center and spreads towards the edges. Hence, the observed growth features on the crystal surfaces can be attributed to the 2D growth mechanism, particularly the layer growth mechanism. ${ }^{12-14}$

Further, the presence of liquid inclusions in these crystals is studied as their density can reduce the optical transmittance and increase the defect content. The crystals obtained in our present studies are of good quality as most of them are free from visible inclusions. This is also supported by the good optical transmittance (around $80 \%$ ) of the crystal in the visible region. However, some inclusions mostly formed at the edges (Fig.-5b) are of various sizes and shapes viz. ovals, elongated cylinders, and circular blobs. The inclusions trapped at the edges could be due to fluctuations in the supersaturation near the crystal surfaces or the transition from dissolution to growth or perhaps due to growth sector boundaries. ${ }^{14-16}$

\section{Chemical Etching}

The wet-chemical etching is the simplest and commonly used technique to assess the defect content in a crystal. In this process, a crystal surface is treated with a suitable solvent, which can slightly dissolve it. 
The solvent is termed an etchant and the process is termed selective dissolution. The dissolution process, in general, is not uniform, begins at certain preferential sites on a crystal surface producing depressions (regular geometric figures), termed as etch pits or etch figures. It is well known that there is a one-to-one correspondence between dislocations and etch pits. The shape and orientation of these etch pits may depend upon the symmetry of the crystal face, the nature of the etchant and the structure of the crystal. ${ }^{14}$ There have been attempts to understand the etching behavior of these crystals; however, they are not comprehensive. For example, the surface patterns obtained with water in the earlier reports were striations formed due to the dissolution phenomena. ${ }^{9,10}$ However, they are not etch pits, as they do not possess regular geometric patterns. Moreover, the etching time is conflicting between the reports.
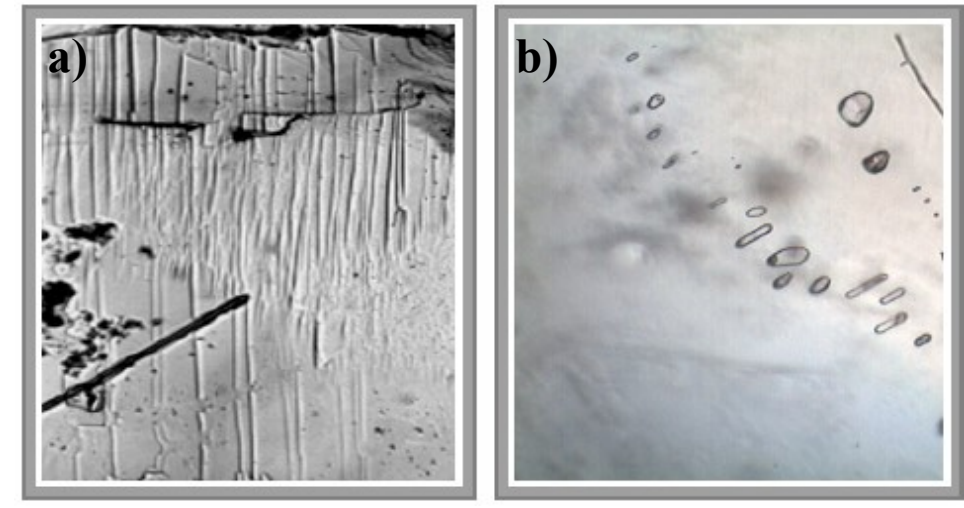

Fig.-5: Microphotographs of L-LMHCl (a) Typical Striations and (b) Inclusions

Hence, in the present work, the chemical etching technique is used to develop new prospective etchants and thereafter, study the density and distribution of dislocations in these crystals. The chemical etching is carried out on the top $\left(\begin{array}{lll}01 & \overline{1}\end{array}\right)$ face of these crystals. In this technique, the crystals are inserted into the etchant/chemical for a specific duration (etching time - e.t) such that the top face always points upwards. The surface is then dried with soft tissue paper and observed under the microscope. Of the several chemicals tried (Table-1) to develop a suitable etchant (which can reveal dislocations), methanol and formic acid produce polishing action of the crystal surface, whereas, acetic acid and propionic acid have shown etching action. The other chemicals have produced no etching action. Propionic acid (e.t $\sim 5 \mathrm{sec}$ ) produces ill-defined elongated rectangular etch pits (Fig.-6a), whereas one can find the best etching action with acetic acid (e.t $\sim 10 \mathrm{sec}$ ), as shown in Fig.-6b.

Table-1: Etching Action on L-LMHCl Crystals
\begin{tabular}{l|l}
\hline Etchant & Etching Action \\
\hline Water & No etching \\
\hline Methanol & Polishing action \\
\hline Ethanol & No etching \\
\hline Propanol & No etching \\
\hline Acetic Acid & Rectangular etch pits \\
\hline Formic Acid & Polishing action \\
\hline Propionic Acid & Ill-defined etch pits \\
\hline Xylene & No etching \\
\hline
\end{tabular}

The etch pits are elongated rectangular, with a long side parallel to the longer edge of the crystal face. To correlate etch pits with dislocation sites, successive etching of crystal surface is carried out. The size of the pits increases with time, as shown in Fig.-6(b, c, and d), reflecting their formation at dislocation sites. Further, to understand the etching kinetics, at least five crystals were etched at each specified time. The increase in the size of the pits was measured under a microscope. As we have obtained rectangular etch 
pits for these crystals, the increase in the length of the pits with time is calculated. It has been observed that there is a decrease in etching rate with time, probably due to the establishment of adsorption equilibrium. Further, careful observation on different etched surfaces of these crystals suggests that the distribution of etch pits is more at the edges than in the central region, perhaps due to the presence of growth sector boundaries. ${ }^{14,16}$ The average dislocation density is calculated to be $6.5 \times 10^{3} / \mathrm{cm}^{2}$, which suggests that the crystals grown are of good quality.
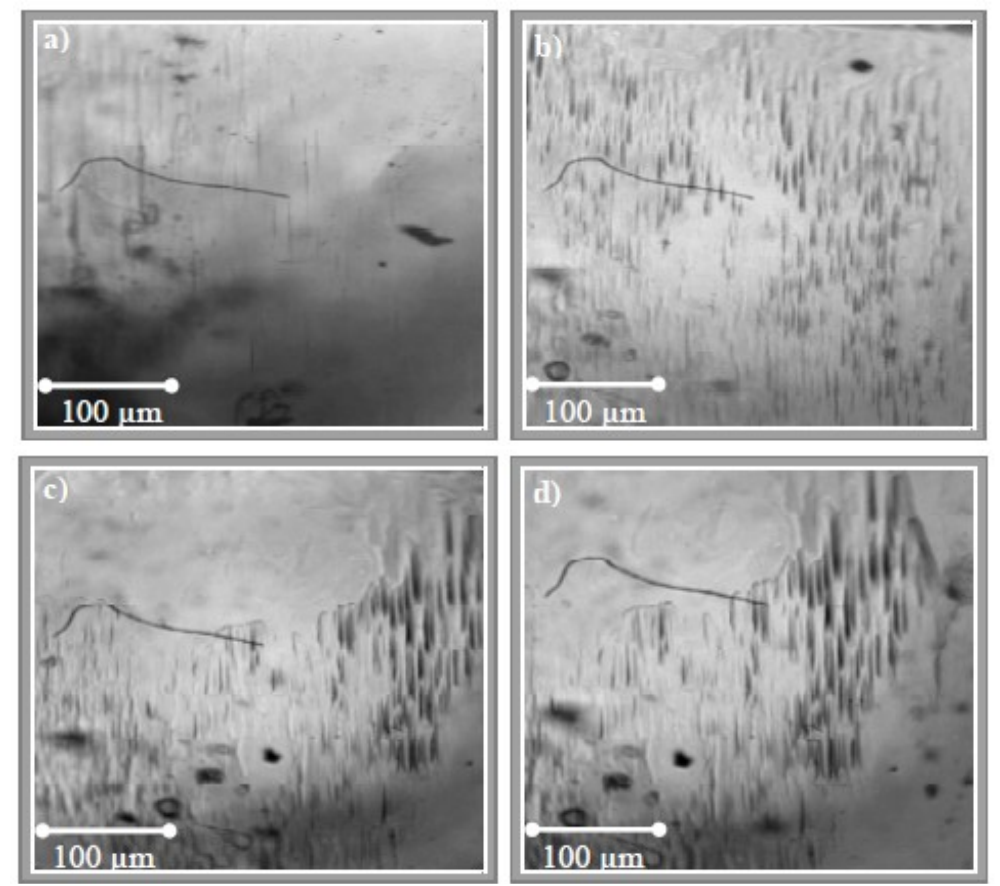

Fig.-6: Etch Pit Pattern on (01) $)$ Face of L-LMHCl crystal with (a) Propionic Acid (e.t $\sim 5 \mathrm{sec}$ ), (b) Acetic Acid (e.t $\sim 10 \mathrm{sec}$ ), (c) Acetic Acid (e.t $\sim 15 \mathrm{sec}$ ) and (d) Acetic Acid (e.t $\sim 20 \mathrm{sec}$ )

\section{Anisotropy in Hardness}

Indentation hardness testing is widely used for assessing the mechanical strength and anisotropic nature of crystals. For this purpose, as-grown L-LMHCl crystals are placed on a circular stage, wherein the crystal can be rotated through known angles. Two sets of indentation impressions were recorded over the entire load range such that one of the diagonals of the indentation impression makes a) $0^{\circ}$ or parallel to the longer edge of the top ( $01 \overline{1}$ ) face of the crystal i.e., $d \| 0^{\circ}$ and b) makes $45^{\circ}$ to the longer edge or earlier indentation orientation i.e., $d \| 45^{\circ}$. Indentations on the sample surface were made at each load (and orientation) at least five times. In the process, the separation between any two indentations was kept large enough to rule out any surface effects, which otherwise affect the size of the impression and hence hardness. The hardness value $H_{v}$ was measured using the relation:

$$
H_{v}=1854.4\left(P / d^{2}\right)
$$

Where, $P$ - applied load in $\mathrm{g}, d$ - diagonal length of indentation impression in $\mu \mathrm{m}$, and hardness in $\mathrm{kg} / \mathrm{mm}^{2}$.

Figure-7a shows the load-hardness curves with error bars for both orientations. The crystal orientation did not distort the indentation impression by any means. It can be observed from the figure that the $H_{v}$ value is higher when the indentation diagonal is parallel to the edge of the crystal than when it makes an angle $45^{\circ}$ for all the loads. It can be observed from the Fig.-7a that $H_{v}$ rapidly increases up to $35 \mathrm{~g}$ and thereafter steadily raises attaining almost load-independent values of $56 \mathrm{~kg} / \mathrm{mm}^{2}\left(d \| 0^{\circ}\right)$ and $49 \mathrm{~kg} / \mathrm{mm}^{2}\left(d \| 45^{\circ}\right)$ 
beyond $70 \mathrm{~g}$. The initial increase in hardness with applied load is termed the reverse indentation size effect. The lower value of hardness at initial loads is due to easy generation and propagation of dislocations and the load-independent region can be attributed to the rearrangement of dislocations. ${ }^{13,14,17-}$ ${ }^{19}$ The hardness value continues to increase (as almost linear plots) in some earlier reports ${ }^{4.7,9}$, however, in our present studies, the behavior in the load-hardness curves is similar to the understanding developed through the seminal work of Sangwal. ${ }^{18}$ Further, the work deviates from others in capturing the hardness anisotropy at each load. From the figure, it can be concluded that the crystal orientation shows an influence on the hardness, with a variation between 6 and $10 \mathrm{~kg} / \mathrm{mm}^{2}$ with respect to $d \| 0^{\circ}$. It is well known that hardness is defined as the resistance the crystal surface offers to the motion of dislocations, deformation, or damage under applied stress. Perhaps, when the crystal is oriented by $45^{\circ}$, the slip systems become active and assist the motion of dislocations. ${ }^{20,21}$ This results in variation in the size of impression and thereby the observed variation in hardness leading to the anisotropic nature. Further, noticeable cracks start appearing around the corners of the indentation impression beyond $50 \mathrm{~g}$, indicating the brittle nature of the crystal. The relation between the load applied and the measured diagonal length is given by Meyer's law as:

$$
P=A d^{n}
$$

Where, $A$ is a constant and $n$ is Meyer's index (or work-hardening coefficient). ${ }^{22,23}$

The slope of $\ln P$ versus $\ln d$ plots shown in Fig.-7b gives the value of $n$ value. The Meyer's index also changes with orientation, with $n$ values being $2.68\left(d \| 0^{\circ}\right)$ and $2.82\left(d \| 45^{\circ}\right)$ exhibiting anisotropy.
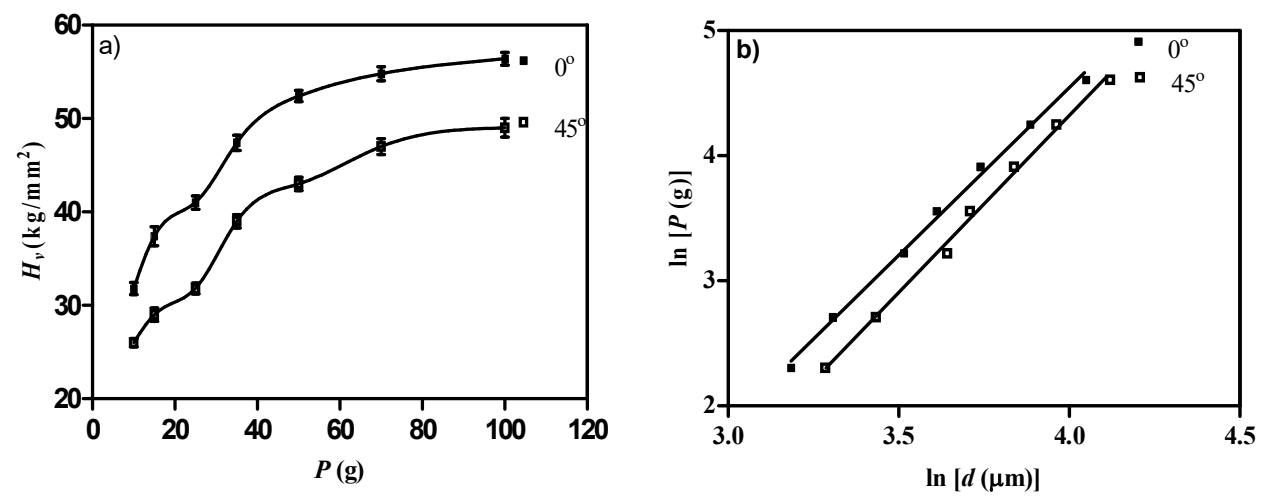

Fig.-7: (a) Variation of Hardness with Applied Load and (b) Meyer's Plot

\section{CONCLUSION}

Highly transparent L-LMHCl crystals with an average growth rate of $0.9 \mathrm{~mm} /$ day (along the longer edge) were obtained from slow evaporation of the saturated solutions. The crystal structure, as well as the functional groups at specific wavenumbers, were identified. Two sharp endothermic peaks were observed in the DSC thermogram and the melting point of the crystal was found to be $263.90{ }^{\circ} \mathrm{C}$. The crystal surface reveals striations that are indicative of a $2 \mathrm{D}$ growth mechanism. The as-grown top face of the crystal is etched with several chemicals and acetic acid was found to be the best etchant. The etching rate initially is high but decreases with time, probably due to the establishment of adsorption equilibrium. The average dislocation density for these crystals is $6.5 \times 10^{3} / \mathrm{cm}^{2}$, which indicates their good quality. The hardness value is less at all loads by 6 to $10 \mathrm{~kg} / \mathrm{mm}^{2}$ for a crystal rotation of $45^{\circ}$, indicating the hardness anisotropy. The activation of slip systems plays a role in the observed decrease in hardness with crystal orientation.

\section{ACKNOWLEDGMENT}

Dr. P.V. Raja Shekar thank the Management, SR University, Warangal for their continuous support in the research activities. Dr. D. Madhavi Latha acknowledges the support through the Women Scientist Scheme-A, DST, New Delhi (SR/WOS-A/PM-1024/2014). 
RASĀYAN J. Chem.

Vol. 14 | No. 3 |1892-1898| July - September | 2021

\section{REFERENCES}

1. C. Justin Raj and S. Jerome Das, Crystal Growth and Design, 8, 2729(2008), https://doi.org/10.1021/cg700800a

2. T. Pal, T. Kar, G. Bocelli and L. Rigi, Crystal Growth and Design, 3, 13(2003), https://doi.org/10.1021/cg025583y

3. B.A. Fuchs, C. Ksyn and S.P. Veisko, Applied Optics, 28, 4465(1989), https://doi.org/10.1364/AO.28.004465

4. R. Ramesh Babu, N. Vijayan, R. Gopalakrishnan and P. Ramasamy, Crystal Research and Technology, 41, 405(2006), https://doi.org/10.1002/crat.200510594

5. A. Senthil, R. Ramesh Babu, N. Balamurugan and P. Ramasamy, Journal of Crystal Growth, 311, 544 (2009), https://doi.org/10.1016/j.jcrysgro.2008.09.056

6. R. Ramesh Babu, K. Sethuraman, N. Vijayan, G. Bhagavannarayana, R. Gopalakrishnan and P. Ramasamy, Crystal Research and Technology, 41, 906(2006), https://doi.org/10.1002/crat.200510693

7. D. Kalaiselvi, R.M. Kumar, and R. Jayavel, Materials Research Bulletin, 43, 1829(2003), https://doi.org/10.1016/j.materresbull.2007.07.004

8. R. Robert, C. Justin Raj and S. Jerome Das, Current Applied Physics, 10, 670(2010), https://doi.org/10.1016/j.cap.2009.08.019

9. V. Vasudevan, R. Ramesh Babu, G. Bhagavannarayana and K. Ramamurthi, Materials Chemistry and Physics, 124, 681 (2010), https://doi.org/10.1016/j.matchemphys.2010.07.033

10. N. Rani, N. Vijayan, K.K. Maurya, D. Haranath, S. Parveen, R. Brijesh, M.A. Wahab and G. Bhagavanarayana, Spectrochimica Acta Part A, 97, 871(2012), https://doi.org/10.1016/j.saa.2012.07.036

11. K. Sangwal, Progress in Crystal Growth and Characterization, 19, 237(1989), https://doi.org/10.1016/0146-3535(89)90005-1

12. P.B.V. Prasad, Crystal Research and Technology, 21, 537(1986), https://doi.org/10.1002/crat.2170210421

13. P.V. Raja Shekar and D. Madhavi Latha, International Journal of Mechanical Engineering and Technology, 9, 248 (2018), https://doi.org/ijmet 09_13_027

14. P.V. Raja Shekar, D. Nagaraju, Ch. Sateesh Chandra, D. Madhavi Latha and K. Kishan Rao, Solid State Sciences, 107, 106353 (2020), https://doi.org/10.1016/j.solidstatesciences.2020.106353

15. K. Kishan Rao and V. Surender, Bulletin of Materials Science, 24, 665(2001), https://doi.org/10.1007/BF02704018

16. H.L. Bhat, Progress in Crystal Growth and Characterization, 11, 57(1985), https://doi.org/10.1016/0146-3535(85)90029-2

17. P.V. Raja Shekar, D. Nagaraju, V. Ganesh and K. Kishan Rao, Crystal Research and Technology, 44, 652(2009), https://doi.org/10.1002/crat.200800516

18. K. Sangwal, Materials Chemistry and Physics, 63, 145(2000), https://doi.org/10.1016/S02540584(99)00216-3

19. K. Kumar, K. Selvaraju, P. Baskaran, N. Senthilvelan and Rajarajan, Rasayan Journal of Chemistry, 11, 915(2018), https://doi.org/10.31788/RJC.2018.1121655

20. S. Karan, and S.P. Sen Gupta, Materials Science and Engineering: A, 398, 198(2005), https://doi.org/10.1016/j.msea.2005.03.016

21. Ch. Sateesh Chandra, D. Nagaraju, P.V. Raja Shekar, T. Tirumal Rao and N. Gopi Krishna, AIP Conference Proceedings, 1665, 100025(2015), https://doi.org/10.1063/1.4918053

22. H. Arul, D.R. Babu and R.E. Vizhi, Rasayan Journal of Chemistry, 11, 511(2018), https://doi.org/10.31788/RJC.2018.1121933

23. A. Mohamed Ibrahim and S. Arunachalam, Rasayan Journal of Chemistry, 12, 1219(2019), https://doi.org/10.31788/RJC.2019.1235172

[RJC-6090/2020] 